\title{
People plus Technology: New Approaches to Sustainable Mobility
}

\author{
RALF BRAND
}

This issue owes its existence to the 4th Dubrovnik Conference on Sustainable Development of Energy, Water and Environment Systems, held in Dubrovnik, Croatia 4-8 June 2007. The main conference theme was transport and therefore papers and sessions 'devoted to different aspects of transport, including engineering, social, and environment aspects' (4th Dubrovnik Conference, 2006) were particularly invited. The conference was intended as a new kind of venue for 'the dissemination, exchange and promotion of new ideas for the interdisciplinary, multicultural and multi-criteria evaluation of complex systems [through] inter-disciplinary partnership ... [of] leading experts in physical, life and environmental sciences, engineering, economic and social sciences' (Ibid.). This sounded very attractive for someone with an interest in bridging disciplinary boundaries for the exploration of synergistic potential between social, institutional and technical aspects of sustainability in general and sustainable transport in particular.

The second paragraph of the invitation, however, was not completely congruent with the expectations raised initially. It described - and thereby implicitly defined - transport problems in narrow engineering terms such as 'transport structure, introduction of hybrid vehicles, increase of efficiency of transport systems, development of new fuels, as biofuels, hydrogen and electricity, and development of pollution control' (4th Dubrovnik Conference, 2006). I could not keep myself from mentioning this to the conference organizers and received, in return, a friendly invitation to remedy the situation with a special session on exactly these linkages between technical and social aspects of the sustainable transport challenge. From there on, one step led to another and the endresult is in front of you. It is the compilation of the most relevant papers presented during said conference session, which was entitled 'Sustainable Socio-Technical Mobility Systems - Inspirations from and for the STS Community', plus two separately commissioned articles.

\section{Science and Technology Studies}

The acronym STS stands for Science and Technology Studies (sometimes also referred to as Science, Technology and Society Studies), a research tradition whose roots are often located in the Sociology of Science of the 1960s. This debate, including Thomas Kuhn's (1962) and Latour and Woolgar's work (1979), revolved around the question of how the production of scientific knowledge really works. This concern was soon expanded to the realm of technology where scholars like Pinch and Bijker (1984) helped to disentangle the complex web of factors and actors that lead to the development, stabilization and adoption (or failure) of new technologies. But not only was, and is, this social shaping dynamic of technologies a matter of interest to STS scholars, many are also concerned with the social impact of technologies in terms of their influence on our daily lives, our identities and behaviours. This is not understood as a form of determinism but 
as the acknowledgement of the mediating role of all kinds of artefacts like microwaves (Cowan, 1983), computers, medicine or, in our case, the built environment. Considering both the social shaping and the social impact of technology, there is wide agreement amongst STS scholars about the bi-directional relationship between the social and the technical. In other words, they reject the idea that either category has ultimate primacy or that either is the unmoved mover. This explains STS scholars' generous use of the compound adjective 'socio-technical'.

\section{Systems Thinking}

Although the prospective authors come from a wide range of disciplines, it is the expression 'socio-technical mobility system' in the conference session title and its implied ontological assumptions that unites them. They all interpret the phenomenon of mobility as constituted of complexly and dynamically interwoven social, institutional and technical factors. The latter include not only valve heads, catalytic converters and other technologies that are meant to reduce the environmental impact of mobility without any change of social practices; they also - and prominently so - include road surface textures, street layouts, pedestrian precincts, bicycle lanes, speed bumps, underpasses, building designs and all other kinds of urban artefact that have an intended or unintended impact on our mobility choices. For example, employees working in a building with no shower are understandably reluctant to cycle to work. In short, the built environment and social mobility practices are inherently intertwined and constitute key components of a system of mutually shaping parts.

The contributors to this issue therefore agree on the importance of 'systems thinking', but we realize that this term is already occupied in very specific senses by different groups. We do not subscribe to its interpretation by complexity theorists who try to capture the dynamics of various systems quantitatively by modelling the causal linkages between all its constituent parts. While we do not want to discredit these approaches, we focus our effort on trying to understand the quality of these linkages. We think that much would already be gained if a consensus could be reached that mobility is not to be understood as the movement of discrete objects but as a system that includes elements such as the automobile industry, consumerist lifestyles, environmental resource use, global procurement of oil, societal values, community cohesion and, of course, spatial planning, urban design, neighbourhood layout, street design and architecture (see Urry, 2004).

But we are not there yet. A vast proportion of intellectual, political and financial effort is still invested in finding and implementing quick technical fixes that require no user attention, let alone compliance. The cliché actor in this agenda is the clever engineer, supported by marketing experts who 'roll out' a laboratory-born innovation which tacitly produces more or less miraculous efficiency gains. The attractiveness of this approach might have to do with the fact that allegedly simple solutions sell better, both as products to all kinds of clients and as stories to the media and general public. The latter, communicative advantage might also explain why clean-cut approaches have more friends in academic circles: they sit neatly within the remit of specific disciplines. The alternative, systemic, sociotechnical approach with its emphasis on the dynamic relationship between the social, institutional and technical, however, does not address such neatly delineated issues but straddles the boundaries of several disciplines such as architecture, urban planning, civil engineering, policy, sociology or environmental psychology.

\section{Related Literature}

Among the existing studies that adopt such a systemic view of mobility is Hoogma et 
al.'s (2002) analysis of different approaches to sustainable transport in eight European cities and Brand's (2005) investigation of Hasselt's mobility policy. Also Guy, Evans and Marvin's (2005) description of sustainable transport strategies in the 'reflexive city' and Hamilton-Baillie's work (2004) fall into this category. Explicitly or implicitly, all of them employ the concept of a co-evolution between technical, social and institutional factors to describe what is happening in our cities - regardless of whether we acknowledge and pay attention to such recursive and messy dynamics. What socio-technical studies of sustainable mobility systems have in common is a recommendation to embrace the concept of co-evolution and to bid farewell to myopic hopes in either technical or social 'fixes' in favour of a more holistic or systemic view of our challenge. This approach requires interdisciplinary collaboration to develop not only a better grasp of socio-technical systems but also effective policy advice on how to make such systems more sustainable. Although such ways of thinking have not made their way into all national, regional and local governments it is encouraging to detect a growing academic literature with such a conceptual focus. Sheller and Urry (2006) even go so far to proclaim a 'new mobilities paradigm' based on their observation of the lively debate around sustainable mobility in the social sciences that transgresses conventional disciplinary boundaries. They explicitly classify 'science and technology studies (STS)' as one of six new types of discourses about mobility, exemplified by the work of Law (2006), Marvin and Medd (2006), Kesselring (2006), Kellerman (2006) and others. Key institutions and individuals working in this area joined their efforts in the 'Cosmobilities Network', which explicitly mentions STS as one of its key conceptual perspectives (Cosmobilities Network, 2008). ${ }^{1}$

This issue of Built Environment stands in this tradition of new approaches to understanding mobility and tries to push the agenda even further. It is unique because it combines the conceptual and analytical notion of socio-technical systems with the normative and substantive issue of sustainability. It therefore resonates closely with Banister's work (2007), which simultaneously addresses two paradigm shifts: one in mobility research as described by Sheller and Urry (2006), the other in the discourse about the economic, ecological and social conditions of our future - condensed in the idea of sustainable development. While Banister focuses on the United Kingdom only, the contributors to this issue study cases not only from the UK but also from Colombia, Denmark, the Netherlands, Belgium and Thailand. This geographical diversity reveals the numerous national and cultural specificities and thus underlines the importance of various nontechnical factors in the creation of sustainable mobility systems. It also permits international comparisons and is complemented by the disciplines represented by the authors - architecture, urban studies, planning, sociology, engineering, history, geography. I suggest readers do not attempt to rank the inherent usefulness of these various approaches and to seek out the best one. If a particular approach is unfamiliar it might make sense to spend extra effort in trying to see through these lenses. After all, different, yet equally important, aspects of sustainable sociotechnical mobility systems become visible only from different angles.

\section{Contributions}

If it is justified to criticize a certain lack of social science thinking among technophile approaches to sustainable development it seems equally valid to complain about insufficient technical knowledge among those who specialize in the social dynamics of the sustainability challenge. While most contributions to this issue focus more on the former type of problem, Peter Cox equally informs both ways of thinking with his paper, The Role of Human Powered Vehicles in Sustainable Mobility. His previous hands- 
on experience as producer of alternative bicycles certainly makes him one of the most technically-savvy members of a Department of Social and Communication Studies. He explains not only some technical aspects of human powered vehicles but also the interface between the social and the technical, including the built environment, that codetermine(d) their previous, and likely future, success or failure. Hardly any author before has investigated the relationships between these artefacts and mobility practices in one analysis - a fruitful step of crucial importance as Cox aptly demonstrates.

Ben Hamilton-Baillie's paper. Shared SpaceReconciling People, Places and Traffic, is a direct result of his experience as a consultant for innovative urban design solutions that aim to reconcile the spatial needs of pedestrians, bicyclists, car users, truck drivers etc. $\mathrm{He}$ argues - and demonstrates with examples from his own and others' work - that people have a much higher inbuilt capacity for appropriate traffic behaviour than assumed by proponents of disciplining artefacts such as traffic lights, bollards, signs, kerbs etc. The concept of 'shared space' which HamiltonBaillie advocates hands responsibility for civilized traffic behaviour back to all users of urban space where previously artefacts tried to embed, signal and enforce the desired behaviour. The result is quite a different, more people-friendly kind of urban space with much less clutter and, so he argues, smoother traffic flows and fewer accidents.

In my own contribution, Co-evolution of technical and social change in action, I present the mobility policy of the Belgian city of Hasselt as a successful case of a strategic synchronization of technical and social change. Its underlying principle is the attempt to make more sustainable behaviours attractive through a coherent set of policy, social and urban design interventions. What makes this case successful is not just its massive scale but the synergistic coherence of all measures. Hasselt therefore seems to be a case from which advocates of sustainable mobility - technophiles and technophobes alike - can learn. I hope to facilitate this learning process with a descriptive and analytical distillate of this complex success story which can be subsumed as a call for 'closing the total chain of people's experiential needs'.

The paper, Urban Transport Systems in Bogotá and Copenhagen: An approach from STS, is the result of a collaboration between the Colombian scholar Andrés Valderrama and his Danish colleague Ulrik Jørgensen. They are primarily interested in the social shaping process of mobility-related artefacts like bus lanes, metro stations, bus platforms, public transport networks etc, empirically studied on the basis of Bogotá's Transmilenio and Copenhagen's Metro. Their two main theoretical angles, LTS (Large Technological Systems) and ANT (Actor Network Theory), are typical of STS ways of thinking and allow them to elucidate, again, the socio-technical and systemic dimension of urban mobility prob-lems and solutions. This is an important point to stress because it protects us from the naïve and apolitical assumption that any best practice lesson can be implemented over night.

Richardson and Jensen's paper, Making mobile subject types at the socio-technical interface, sheds light on a rather underexposed aspect of sustainable development in general and in sustainable mobility in particular: its social dimension. Here, of Bangkok's Sky Train. Their theoretical position assumes that not only mobility behaviours are sociotechnically configured but also identities and inequalities. To test this hypothesis they analyse the interface between hard infrastructures and soft practices of everyday life as products of the struggle for influence between the state, private capital, middleclass travellers and the urban poor. They conclude that the entire infrastructural setup of the Sky Train (its routing, design, platforms, elevated construction etc.) is indeed the product and producer of a certain kind of urban mobility elite. In other words, social inequality is materially (re-)produced. 


\section{'Provisional' Conclusion}

Given the conceptual point of departure of this issue that not only the impact but also the social shaping of urban artefacts needs to be considered in a holistic, socio-technical understanding of sustainable mobility systems, it is hoped that these articles will be of use not only to academics, but also to politicians, civil servants, planning practitioners, architects and 'ordinary' citizens. We never presumed to provide cookbookstyle advice for urban practitioners, but we hope to raise their critical awareness of the socio-technical nature of sustainable mobility systems. We hope that this issue will help them appreciate the fact that their decisions may have a wider bearing, intended or unintended, on a more sustainable future than previously realized - and wider than often acknowledged by advocates of either technical or social 'fixes'. If pressed for one piece of policy advice, most contributors would probably agree to recommend a mode of thinking that does justice to the interrelatedness of technical, social and institutional factors. Metaphorically speaking, we should adopt some kind of hub-spokeand-rim model of sustainable mobility. The focus of our attention, a sustainable mobility system, sits in the middle (hub) and is held in place by many other factors (spokes) which, in turn, are themselves connected with each other (rim). Fortunately, this awareness is beginning to trickle into city halls and ministries. The German National Cycling Plan, for example, has as its core motto 'cycling as a system' (BMVBW, 2002, emphasis added).

Such advice is still quite abstract, however. If researchers and analysts want to make a difference they need to make much more concrete recommendations. The contributors here certainly have some thoughts on this and are already contributing to more sustainable mobility systems as consultants to a variety of clients. And while they mostly agree on abstract issues, they do not agree on all details. Some even contradict each other which explains the word 'provisional' in this section heading. Among my own arguments, for example, is an emphasis on carefully planned infrastructural components of a sustainable socio-technical system which can include artefacts such as bicycle lanes, kerbs, signage etc. Hamilton-Baillie, however, makes very good arguments for removing such disciplining or policing objects because they not only clutter our townscapes but also, and even more importantly, because they annul our inborn human skills to negotiate space like the fish in a shoal. Cox and several other authors are in implicit disagreement over the question how ambitious we should be in providing infrastructures for more sustainable mobility choices. If we make cycling-aswe-know-it more attractive we might inadvertently hamper cycling-as-it-could-be (with velomobiles etc.). Richardson and Jensen remind us of the social dimension of sustainable mobility which many mainstream advisers, including some of the authors here, tend to treat a little lightly or take for granted as automatic side-effect.

These unresolved questions highlight the importance of future research. If we take our own call for systems thinking seriously we should employ it in our own work as well. From this angle, then, it is not only the amount and funding of research that matters but its strategic co-ordination. There seem to be four main areas that need to be co-ordinated: firstly, the content of future actions and interventions; secondly, the decision-making processes through which we best arrive at such actions; thirdly the relationship between design process and content; and fourthly, the conceptual tools we use to think about both process and content.

In this issue, it is mostly Cox and HamiltonBaillie who propose and analyse certain contents of design interventions in the built environment. It would certainly be desirable to co-ordinate the future research efforts of scholars whose interest and expertise falls largely in this area. 
A key message of my own contribution revolves around the governance of decisionmaking processes and argues for participatory approaches because they tend to generate effective and socio-technically coherent design content. A number of tools have been developed to facilitate such processes systematically, ${ }^{2}$ but we do not yet know which approach is most suitable for which kind of context. If there is a link between design process and design content - and I certainly believe there is - we do not have sufficient knowledge about it and this justifies a whole research programme in its own right.

Lastly, the cohort of STS scholars has filled many metres of library shelves about the recursive hen-and-egg relationship between the technical and the social but very little is known about it in the specific context of the built environment, let alone sustainable mobility systems. Valderrama and Jorgensen help us in this regard by testing the usefulness of certain STS-typical tools-tothink-with for the context of sustainable mobility. Also Richardson and Jensen do this with the concept of mobile subject types.

In this sense I hope that this issue of Built Environment provides modest assistance in walking the next step towards more sustainable mobility systems (by aiding urban practitioners in their far-ranging decisions) and to think about the one after that (by inspiring researchers in their search for key research questions and grant makers to devise strategic funding programmes). In all cases, what we ultimately aim for are mobility systems that are not only technically feasible but also socially accepted and used.

\section{NOTES}

1. The Cosmobilites Network website (www. cosmobilities.net) provides links to many resources for further reading.

2. Prime examples include Strategic Niche Management (SNM), Constructive Technology
Assessment (CTA), Co-Evolutionary Sociotechnical Scenario Method (CEST) or Constructive Co-evolution Audit (CCA).

\section{REFERENCES}

4th Dubrovnik Conference (2006) First announcement - An invitation to authors, participants and sponsores. Available at <http://www.dubrovnik2005.fsb.hr / 2007DubrovnikConference_FA.pdf $>$. Accessed 6 April 2008.

Banister, D. (2007) Is paradigm shift too difficult in U.K. transport? Journal of Urban Technology, 14(2), pp. 71-86

Brand, R. (2005) Synchronizing Science and Technology with Human Behaviour. London: Earthscan.

Bundesministerium für Verkehr, Bau- und Wohnungswesen (BMVBW) (2002) FahrRad! Nationaler Radverkehrsplan 2002-2012 [Cycle! - National cycling mobility plan 2002-2012] Berlin. Available at http://www.bmvbs.de/ Anlage/original_11561/Radverkehrsplan-20022012.pdf. Accessed 31 March 2008.

Cosmobilities Network (2008) Welcome. Available at http://www.cosmobilities.net/index.php? id=16. Accessed 11 January 2008.

Cowan, Ruth Schwarz (1983) More Work for Mother: The Ironies of Household Technology From the Open Hearth to the Microwave. New York: Basic Books.

Guy, S., Evans, R. and Marvin, S. (2005) Multiple pathways to sustainable transport futures - Experts, users and the planning process, in Rohracher, H. (ed.) User Involvement in Innovation Processes. Munich \& Vienna: Profil, pp. 245-263.

Hamilton-Baillie, B. (2004) Urban design: Why don't we do it in the road? Modifying traffic behavior through legible urban design. Journal of Urban Technology, 11(1), pp. 43-62.

Hoogma, R., Kemp, R., Schot, J. and Truffer, B. (2002) Experimenting for Sustainable Transport: The Approach of Strategic Niche Management. London: Spon.

Kellerman, Aharon (2006) Personal Mobilities. London: Routledge.

Kesselring, S. (2006) Pioneering mobilities: new patterns of movement and motility in a mobile world. Environment and Planning A, 38(2), pp. $269-279$.

Kuhn, Thomas, S. (1962) The Structure of Scientific 
Revolutions. Chicago: University of Chicago Press.

Latour, Bruno and Woolgar, Steve (1979) Laboratory Life: The Construction of Scientific Facts. Beverly Hills: Sage.

Law, J. (2006) Disaster in agriculture: or foot and mouth mobilities. Environment and Planning $A$, 38(2), pp. 227-239.

Marvin, S. and Medd, W. (2006) Metabolisms of obecity: flows of fat through bodies, cities, and sewers. Environment and Planning A, 38(2), pp. 313-324.
Pinch, Trevor J. and Bijker, Wiebe E. (1984) The social construction of facts and artefacts: or how the sociology of science and the sociology of technology might benefit each other. Social Studies of Science, 14, pp. 399-441.

Sheller, M. and Urry, J. (2006) The new mobilities paradigm. Environment and Planning A, 38(2), pp. 207-226.

Urry, John (2004) The system of 'automobility'. Theory, Culture and Society, 21(4/5), pp. 25-39. 